\title{
Simulating Flood Urban Drainage Networks through 1D/2D Model Analysis
}

\author{
Yara T. Abdelrahman, ${ }^{1}$ Ashraf M. El Moustafa ${ }^{2}$ and Mohamed Elfawy ${ }^{2}$ \\ ${ }^{1}$ Engineering Consultants Group, Cairo; ${ }^{2}$ Ain Shams University, Cairo.
}

\begin{abstract}
Storm drainage design aims to provide safe travel for vehicles and pedestrians as well as to protect properties from damage during storms. The design process must begin in the early phases of urban planning in order to achieve an effective, efficient and economical system. The main problem is that during $100 \mathrm{y}$ rainfall events, urban drainage systems can become flooded. This is due to the fact that unlike main collector systems, which are designed to accommodate such a flow, urban drainage systems are designed to convey runoff from less frequent storms, around 2 y to $10 \mathrm{y}$. This paper adopts a 1D/2D PCSWMM model to illustrate the dual drainage concept and to investigate how to achieve a more realistic estimate of the coupled flow discharging into a main collector, as well as simulating different scenarios to reduce the damage that could result from extreme events. The results were examined and compared, providing guidance for engineers to reach an optimal storm drainage design. Furthermore, the paper presents different ways to utilize 1D/2D models in simulating multiple solutions for urban flooding.
\end{abstract}

\section{Introduction}

Storm drainage design aims to provide safe travel for vehicles and pedestrians, as well as to protect properties from damage during storms. The design process must begin in the early stages of urban planning in order to achieve an effective, efficient and economical system (Federal Highway Administration 2001).

During 100 y rainfall events, urban drainage systems can become flooded. This is due to that fact that unlike main collector systems, which are designed to accommodate such a flow, urban drainage systems are designed to convey runoff from less frequent storms, around 2 y to 10 y (Federal Highway Administration 2001).

Conventional one-dimensional (1D) models (either steady or unsteady analysis) usually simulate flow in flood channels and gravity collection networks but are inadequate to simulate certain phenomena, such as street flooding and overbank flow in floodplains, that occur during extreme events. Two-dimensional (2D) and 1D-2D models may be used in such situations but their complexity, cost and significant data requirements have limited their application (Leandro 2009).

It is currently easier to adopt 2D models in order to create and analyse a more realistic simulation of both the coupled flow draining into a main collector and a representation of the overland surface and floodplain flows that occur during extreme events. The availability of high quality digital elevation models (DEMs), the increased power of desktop computers, in addition to the need for a more realistic simulation of flooding, have all contributed to the adoption of 2D models for floodplain mapping and the analysis of overland flows (Leandro et al. 2011).

\section{AlAla'alyah Development}

AlAla'alyah is a new development in Saudi Arabia. The project area is $\sim 1 \mathrm{~km}^{2}$. Data collected from previous hydrology studies show the stream paths that will be affected by the study area, shown in Figure 1.

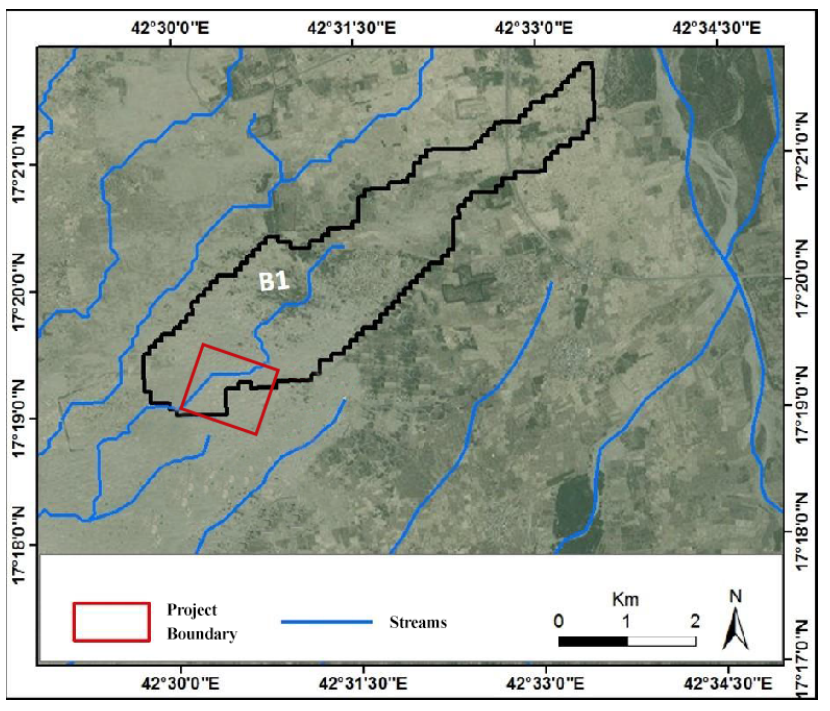

Figure 1 Stream paths and basins affecting the case study.

Since a major stream passes through the project area, a channel was proposed to allow flood flow, as shown in Figure 2. The channel is designed to hold the peak flow resulting from a $100 \mathrm{y}$ return period rainfall event.

Abdelrahman, Yara T., Ashraf M. El Moustafa and Mohamed Elfawy. 2018. Simulating Flood Urban Drainage Networks through 1D/2D Model Analysis. Journal of Water Management Modeling 26: C454. doi: 10.14796/JWMM.C454.

(c) CHI 2018. www.chijournal.org ISSN 2292-6062. 


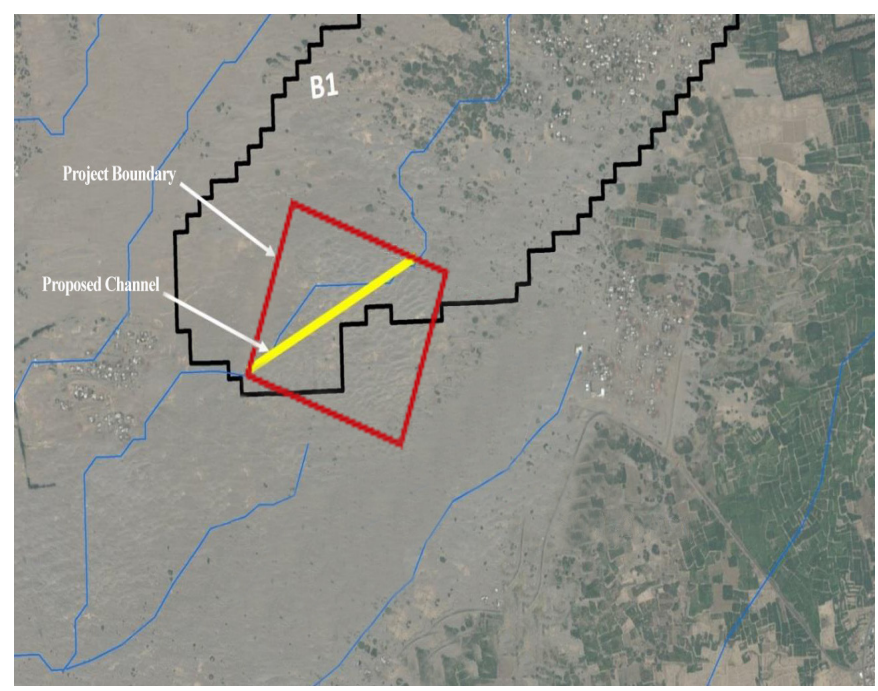

Figure 2 Proposed channel.

The maximum rainfall depth was obtained for storm frequencies of $5 y, 10 y, 25 y, 50 y$ and $100 y$. The respective depth values are shown in Table 1.

Table 1 Maximum rainfall depth at different frequencies.

\begin{tabular}{lccccc}
\hline Return period $(\mathrm{y})$ & 5 & 10 & 25 & 50 & 100 \\
Rainfall depth $(\mathrm{mm})$ & 51.5 & 62.3 & 75.9 & 86 & 96 \\
\hline
\end{tabular}

Figure 3 shows the hydrograph of the channel that crosses the project area for a $100 \mathrm{y}$ return period storm over the watershed. The peak flow is $7.1 \mathrm{~m}^{3} / \mathrm{s}$.

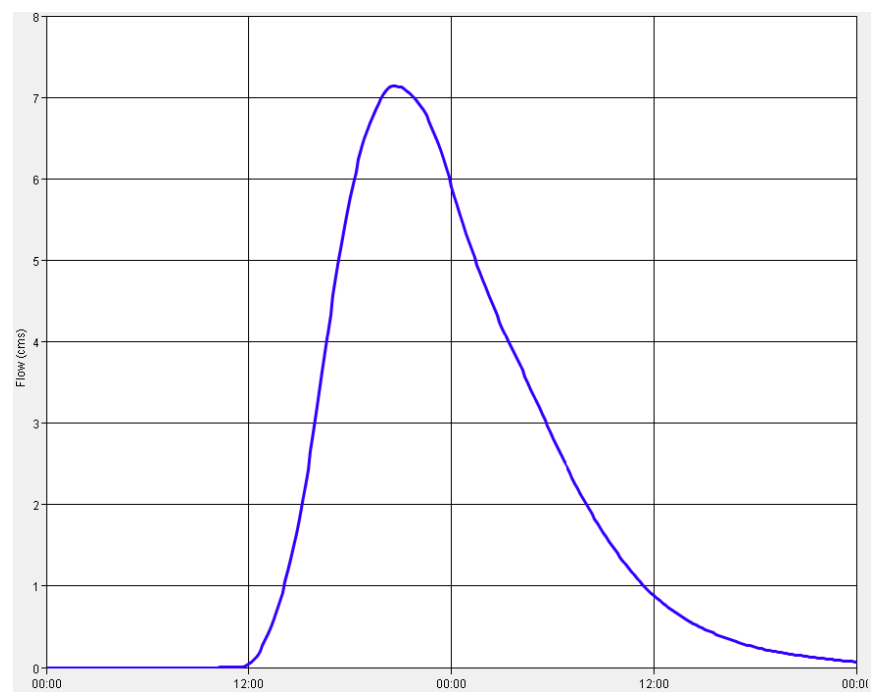

Figure 3 Hydrograph of the stream crossing the project area for $100 \mathrm{y}$ return period storm.

Figure 4 shows the pipe network and pipe diameter distribution on the masterplan and illustrates how the subsurface network is integrated with the channel crossing the study area.

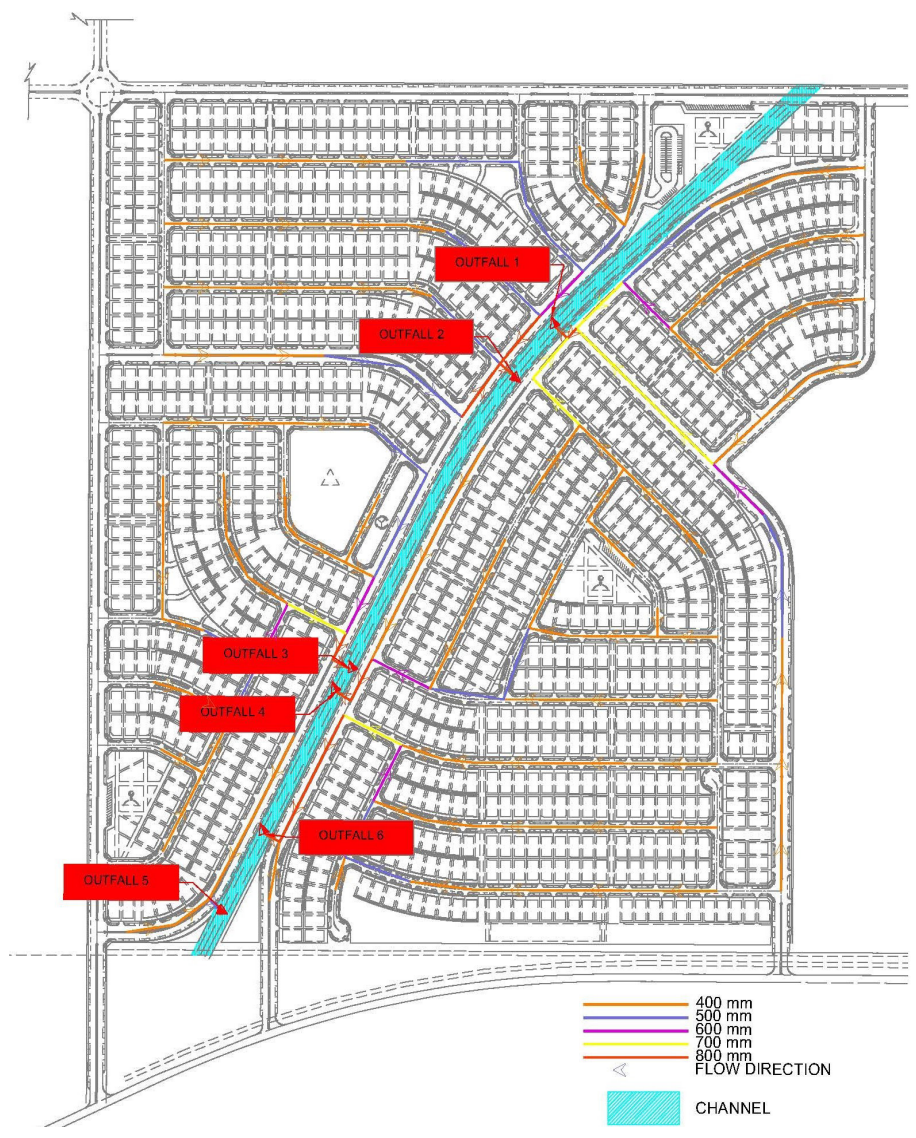

Figure 4 Masterplan of AlAla'alyah showing the proposed pipe network diameter distribution and the channel crossing the case study area.

\section{Methodology}

In this case study, the urban drainage system will be designed to hold the runoff for $10 \mathrm{y}$ rainfall event at most. The size of the channel crossing the project area will be designed to accommodate the runoff from a 100 y rainfall event. During a 100 y rainfall event, if the drainage system is unable to divert the incoming hydrograph volume to the channel crossing the study area, the sewer system will become surcharged and flooding will occur. A 1D-2D model is needed to show how the system will perform during extreme events. The model will also simulate alternatives to assist in making the decision to either accept the flooding or reduce its effects.

\subsection{Unsteady State Analysis Using 1D-2D Ap- proach}

One dimensional-two-dimensional (1D-2D) models link 1D unsteady flow calculations which simulate linear flow in the subsurface network with 2D calculations where the flow is two dimensional. The 1D model uses a link-node system, while the 2D 
domain is defined by a grid of cells that carry attributes of slope and roughness. During extreme storms, water flows out of the subsurface system and may either gravitate towards a neighbouring inlet, or pond in the lack of an adjacent inlet. Obstructions or inadequate capacity in the drainage network may cause flow to backup or reverse direction (Syme et al. 2009).

The program PCSWMM (by CHI) is used to simulate 1D-2D flows. PCSWMM uses the U.S. Environmental Protection Agency (USEPA) SWMM package for numerically solving 1D simulations (Shrestha et al. 2014).

PCSWMM 2D extends the fully dynamic 1D approach in PCSWMM-USEPA SWMM5 to model 2D free surface flow (James et al. 2012). It uses the Saint-Venant equations to solve each component of a computational cell, along a network of junctions and open conduits that represent the problem.

\subsection{Analysis and Results}

A 2D mesh was generated from DEM within the study area. The 2D mesh linkage to the 1D model is illustrated in Figure 5, which shows the final setup of the model prior to starting the analysis.
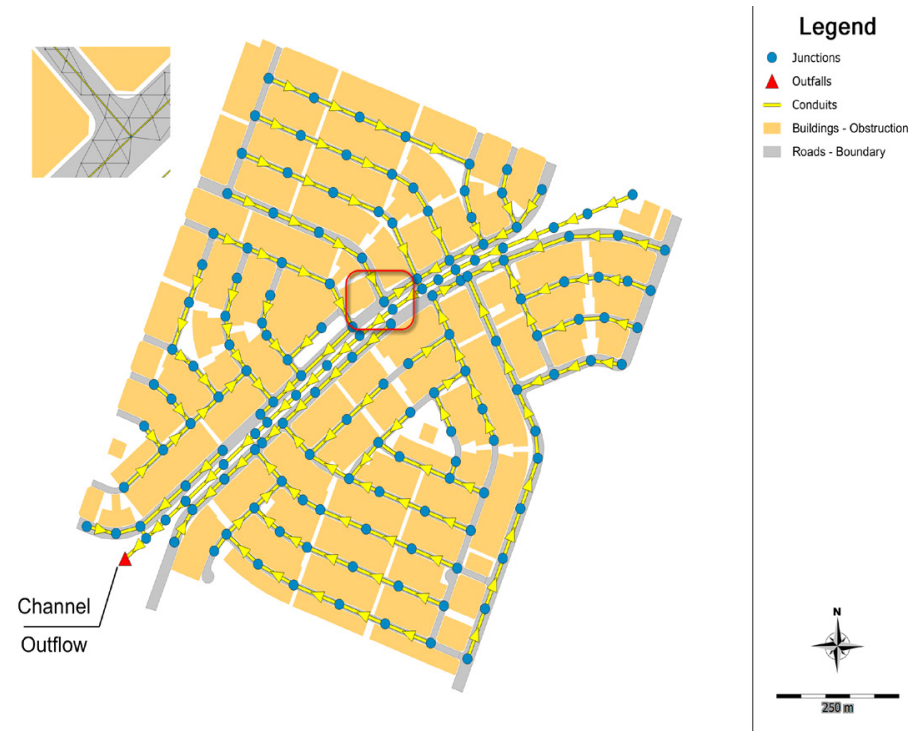

Figure 5 Final setup of the model showing the 2D mesh connected to the 1D network.

Results of the analysis show a flood plain that will be created in the study area. Figure 6 shows the flood plain analysis in which the blue areas represent the maximum water depth locations. The maximum depth occurring during flooding is $0.14 \mathrm{~m}$, and the duration of flooding is $\sim 72 \mathrm{~min}$.

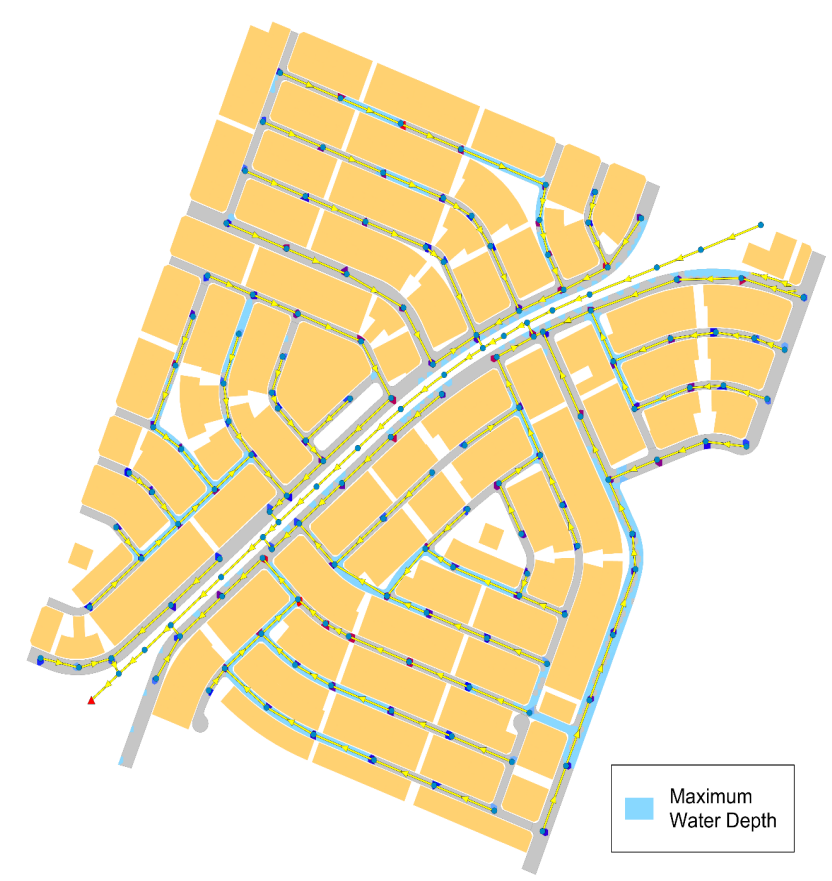

Figure 6 Flood plain analysis.

Figure 7 Shows the flow at the outfall of the channel. There are two peaks in the hydrograph: one is caused by the watershed basin 1 and the other is caused by the study area $\left(9.10 \mathrm{~m}^{3} / \mathrm{sec}\right)$. The peak flows do not occur at the same time. This gives us a more realistic and accurate estimate of the flow discharging into the channel than would be obtained by adding the peak flows of both areas (the study area and the basin) linearly. The peak flow computed for the study area takes into consideration the flooding, ponding and rerouting of the flow through the pipes and roads which provides a more reasonable estimate of the peak flow from the study area.

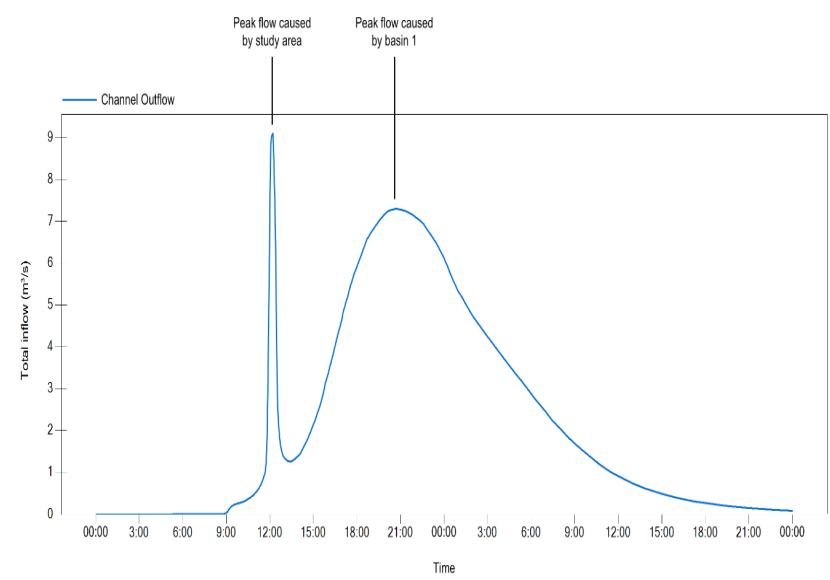

Figure 7 Hydrograph at the outfall of the channel. 


\subsection{Network Alternatives}

Flooding is permissible when analysing a $100 \mathrm{y}$ return rainfall event. However, the ability to view the routing of the flow that is flooding from the manholes allows us to assess the destructiveness of the flood as well as the acceptability of its duration and depth. Consequently we can plan for cost effective solutions that do not involve increasing the pipe diameters.

In this section several alternatives (solutions) are discussed to find an economic solution to reducing the effects of flooding, taking into consideration that flooding is acceptable during extreme events as long as it is not damaging.

The proposed solutions are:

1. Install curb openings at the ponding locations adjacent to the channel to allow the flow to reach the channel faster;

2. Install flushed curb on the roads adjacent to the channel, which will allow the flooding to flow to the channel by surface drainage; and

3. Reduce the pipe diameters and check if the duration of flooding and ponding depth is acceptable.

\section{Install Curb Openings}

Installing curb openings at the ponding areas on the roads adjacent to the channel is a cost effective solution, and it will not negatively impact urban planning.

In order to simulate the curb openings, orifices were added to the hydraulic model to connect the mesh with the channel, as shown in Figure 8.

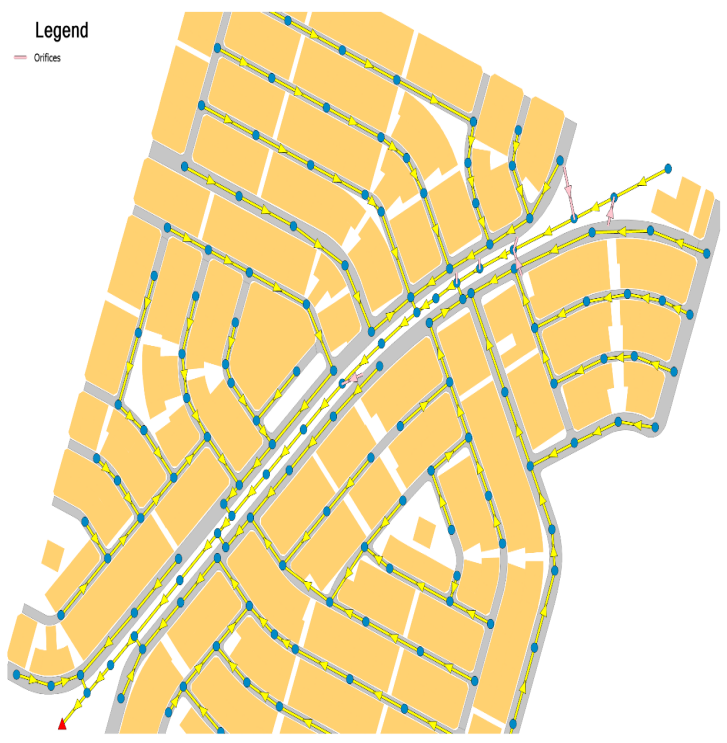

Figure 8 Orifices connecting 2D mesh with channel to simulate curb openings.
Figure 9 shows the ponding area of the case study after applying the curb openings. The maximum depth reached during flooding is $0.14 \mathrm{~m}$ while the duration of flooding is $\sim 58 \mathrm{~min}$.

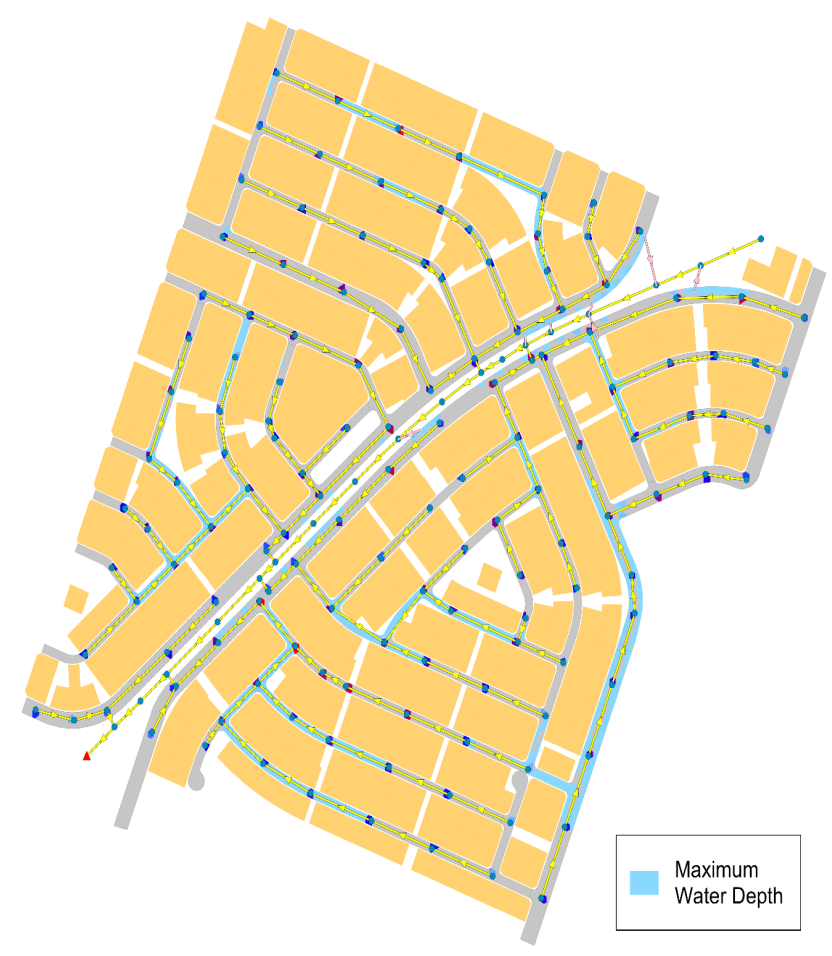

Figure 9 Ponding area after simulating curb openings.

Figure 10 shows the flow of the channel. The peak flow caused by the study area is $9.42 \mathrm{~m}^{3} / \mathrm{sec}$. The flow is significantly higher and the flood duration is remarkably lower than before implementing the curb openings as the flow was rerouted to the channel faster by the curb openings.

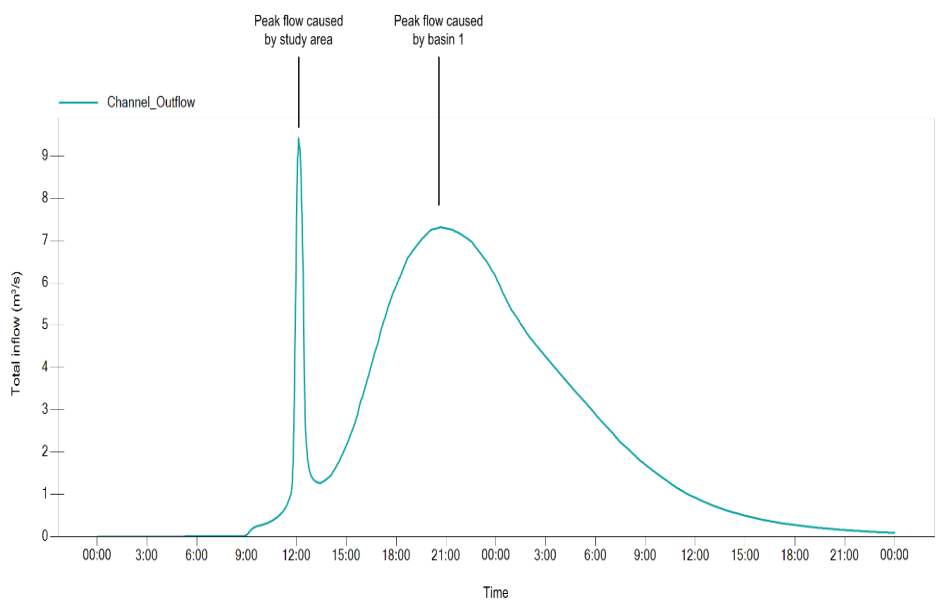

Figure 10 Hydrograph at outfall of the channel after implementing curb openings. 


\section{Install Flushed Curb}

Installing a flushed curb on the roads adjacent to the channel is also a cost effective solution, one that assists in discharging the ponding areas on the roads adjacent to the channel in an economical manner.

To be able to simulate this solution, the boundary layer was modified to include the channel. Accordingly, a new mesh was created that contains the channel, as shown in Figure 11.

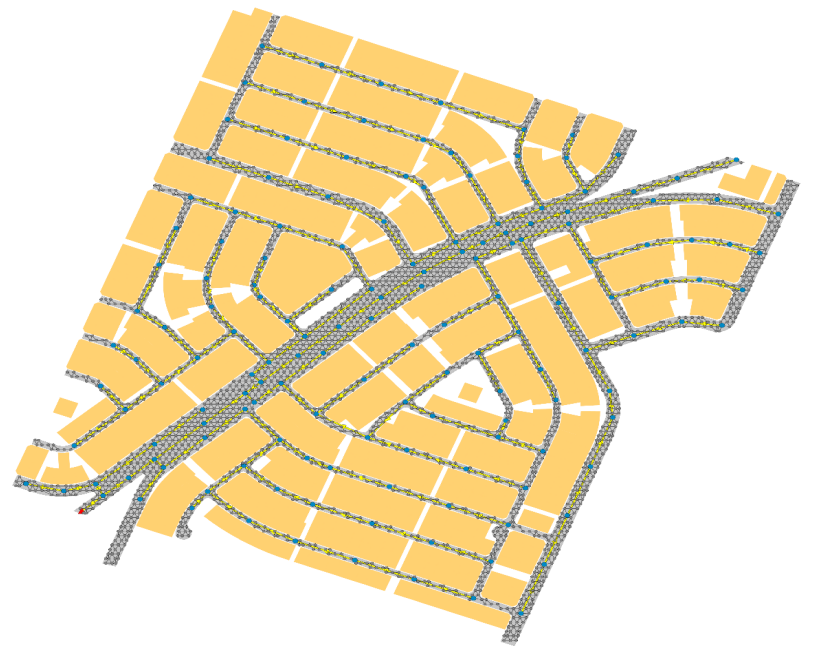

Figure $112 \mathrm{D}$ mesh to simulate flushed curb.

Figure 12 Shows the ponding area of the case study after implementing the flushed curb solution. The largest depth reached during flooding is $0.12 \mathrm{~m}$, and the duration of flooding is $\sim 54$ min.

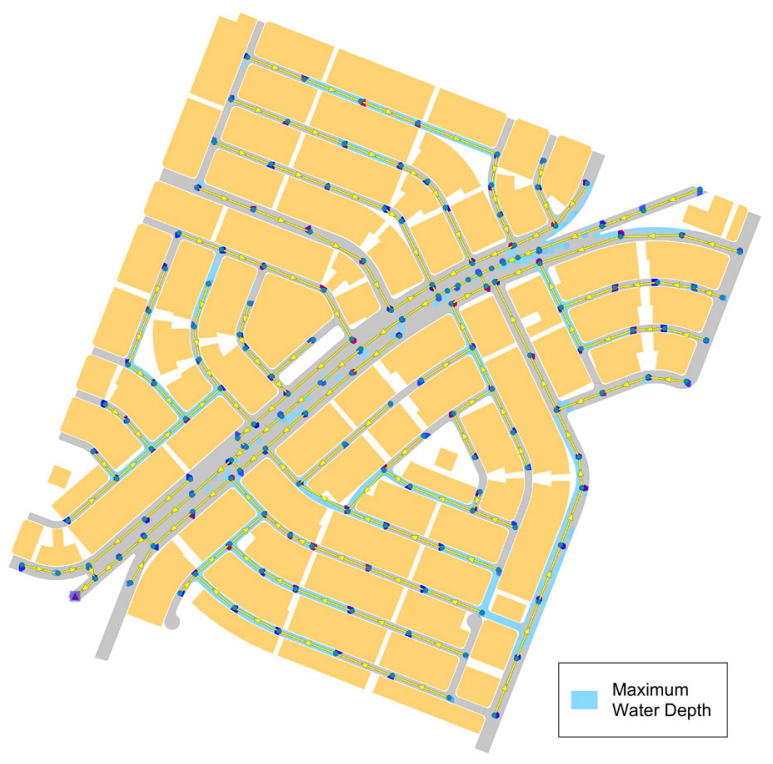

Figure 12 Ponding area after simulating flushed curb.

Figure 13 shows the flow at the outfall of the channel. The peak flow caused by the study area is $9.59 \mathrm{~m}^{3} / \mathrm{sec}$. The flow is also higher than it was originally due to the flow being rerouted to the channel faster.

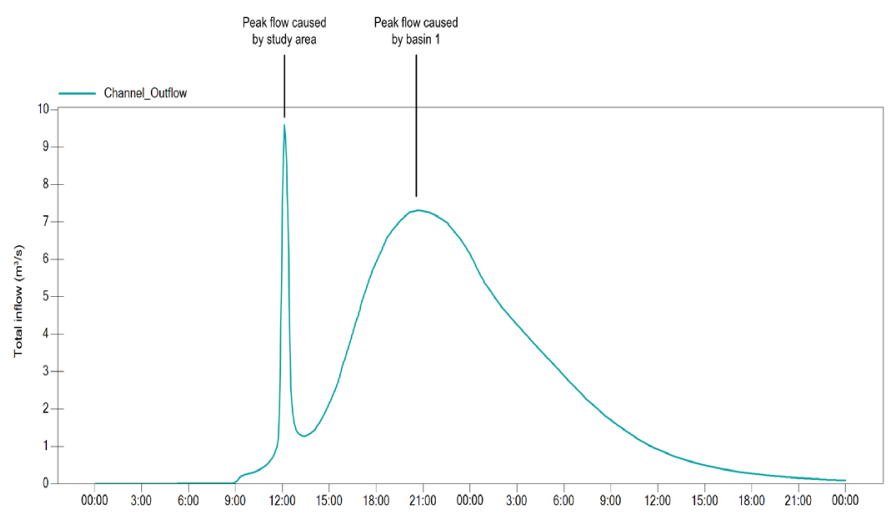

Time

Figure 13 Hydrograph at outfall of the channel after implementing flushed curb solution.

\section{Reducing Pipe Diameters}

Pipe diameters were reduced to $600 \mathrm{~mm}$ maximum to assess whether the flooding duration is acceptable and if this is a more economical solution. Figure 14 shows the reduced pipe network diameter distribution.

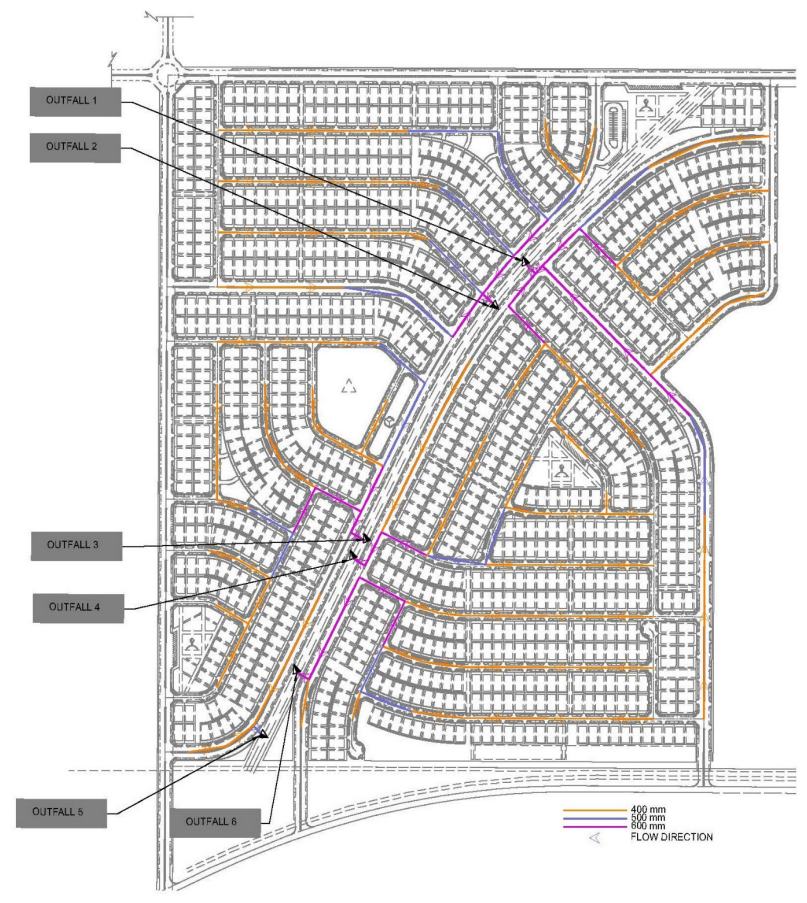

Figure 14 Reduced diameter pipe distribution.

The area of the floodplain increased as a result of the pipe diameter reduction due to the incapability of the reduced drainage network to store the excess flow, as illustrated in Figure 15. The greatest water depth reached during flooding is $0.36 \mathrm{~m}$ 
which is remarkably higher than the previous alternatives, while the duration of flooding is almost 196 minutes.

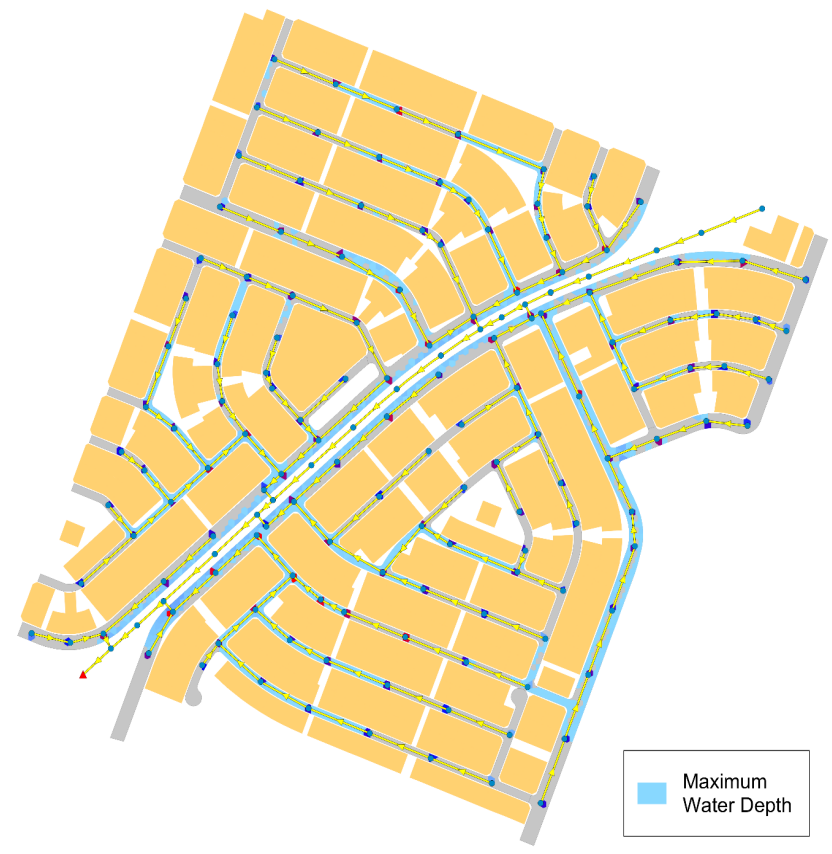

Figure 15 Ponding area after reducing pipe diameters.

Figure 16 shows the flow at the outfall of the channel. The peak flow generated by the study area is $7.41 \mathrm{~m}^{3} / \mathrm{sec}$. This is due to dual drainage caused by the flooding at risers. The flow is notably lower than for either of the first two solution because flooding occurred at risers and the streets are inundated by the flood until the risers and pipes drain enough to contain the flow and reduce the flooding.

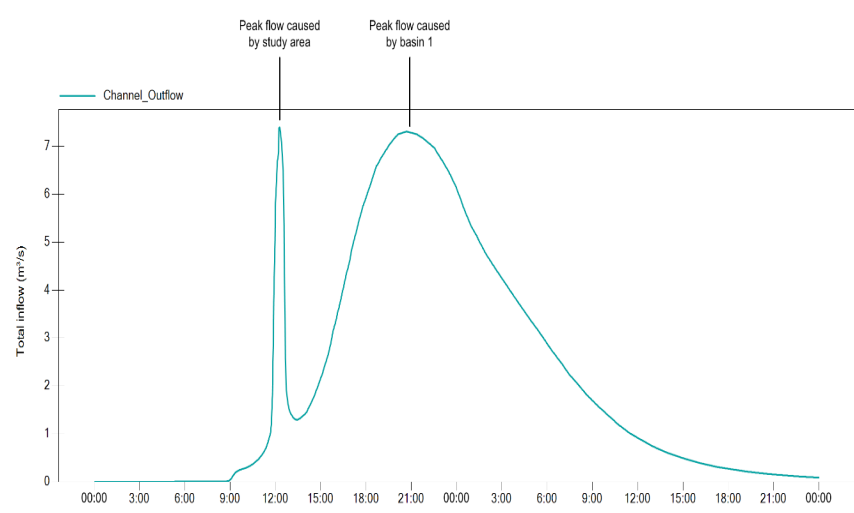

Figure 16 Hydrograph at the outfall of the channel after reducing the pipe diameters.

\section{Conclusion}

Storm network inundation leads to two cases:
- the flooded storm water eventually returns to the storm network; and

- the flooded storm water ponds in certain areas and does not return to the system.

These cases can easily be represented by the 1D-2D stormwater model which is one of its main advantages.

1D-2D models are effective in providing a better understanding of the stormwater network performance, especially during extreme events. They provide a better realization of the pathway of the stormwater, flooding, and ponding locations, thereby allowing the designer to find solutions that reduce storm effects such as catchbasin placement or, as in the case study area, installing curb openings or a flushed curb system.

In some cases, the optimum solution can be to reduce pipe size diameters if the resultant flood duration is acceptable and there is no risk of damaging property or endangering the lives of people. This solution allows for the design of a more economical pipe network, and leads to a reduction in the flow entering the channel due to flow attenuation enabled by the flooding. This allows for decreasing the size of the channel which can lead to an overall thriftier solution.

In a nutshell, a solution should be determined only after viewing the flooding locations simulated by $1 D-2 D$ modeling for a better decision-making process.

Further work could be carried out to examine the effectiveness of additional simulations such as modeling another scenario which combines pipe diameter reduction with implementing curb openings, with a more detailed DEM, and analysis of the cost of each proposal.

\section{References}

Federal Highway Administration. 2001. Urban Drainage Design Manual. Washington, DC: Federal Highway Administration.

Leandro, J., A. S. Chen, S. Djordjević and D. A. Savić 2009. “Comparison of 1D/1D and 1D/2D Coupled (Sewer/Surface) Hydraulic Models for Urban Flood Simulation." Journal of Hydraulic Engineering 135(6). https://doi.org/10.1061/(ASCE)HY.1943-7900.0000037

Leandro, J., S. Djordjević, A. S. Chen, D. A. Savić and M. Stanić. 2011. "Calibration of 1D/1D Urban Flood Models with 1D/2D Model Results in the Absence of Real Data." Water Science \& Technology 64 (5): 1016-24.

James, R., K. Finney, N. Perera, W. James and N. Peyron. 2012. "SWMM5/PCSWMM Integrated 1D-2DModeling." In Fifty Years of Watershed Modelin-Past, Present and Future, edited by A. S. Donigian, Richard Field and Michael Baker Jr. New York: Engineering Conferences International. ECI Symposium Series. http://dc.engconfintl.org/watershed/12.

Shrestha, A., T. Chaosakul, D. P. M. P. Priyankara, L. H. Chuyen, S. S. Myat, N. K. Syne, K. N. Irvine, T. Koottatep and M. S. Babel. 2014. "Application of PCSWMM to Explore Possible Climate 
Change Impacts on Surface Flooding in a Peri-Urban Area of Pathumthani, Thailand." Journal of Water Management Modeling 22: C377. doi: 10.14796/JWMM.C377.

Syme, W. J., R. Jones and L. Arneson. 2009. "Two-Dimensional Flow Modeling of Hydraulic Structures in a 2D ADI Scheme." In
IAHR World Conference Proceedings: 33rd Congress-Vancouver. International Association for Hydro-Environment Engineering and Research (IAHR). 